\title{
Comunicação
}

[Communication]

\section{Compressão de medula espinhal ocasionada por melanoma em cavalo de pelagem castanha}

[Spinal cord compression caused by melanoma in brown coat horse]

\author{
E.M. Busato, R.S. Sousa, J.R. Silva-Meirelles, M.L. Castro, I. Deconto, P.T. Dornbusch ${ }^{*}$
}

Universidade Federal do Paraná - Curitiba, PR

O melanoma é uma neoplasia relacionada aos melanócitos, que acomete preferencialmente cavalos tordilhos com mais de seis anos, sendo detectado com menor frequência em outras pelagens. A apresentação clínica mais comum é a cutânea (Thomassian, 2005), sendo a real incidência de melanomas metastáticos em equinos desconhecida (MacGillivray et al., 2002). Na literatura, existem poucos relatos de compressão espinhal ocasionada por melanoma em cavalos. Rodríguez et al. (1998) descreveram um caso de melanoma metastático em coluna lombar, que causou disfunção neurológica em uma égua tordilha da raça Árabe. Schott et al. (1990) relataram dois casos de compressão espinhal ocasionada por melanoma, sendo um cavalo de 13 anos e uma égua de 22, ambos tordilhos e da raça Árabe. Apesar de melanomas serem mais frequentes em cavalos de pelagem tordilha, quando acometem cavalos de outras pelagens são mais propensos a apresentar comportamento maligno (Sundberg et al., 1977). O objetivo do presente trabalho é relatar um caso de melanoma que ocasionou compressão de medula espinhal em região de coluna torácica (T15 a T18) em um cavalo de pelagem castanha da raça Brasileiro de Hipismo.

Um cavalo castrado, de pelagem castanha, da raça Brasileiro de Hipismo, 15 anos, 520kg, foi recebido pelo Setor de Grandes Animais do Hospital Veterinário da Universidade Federal do Paraná (UFPR), com queixa de ataxia, iniciada há algumas horas e afecção dentária, acompanhada por disfagia e halitose, há dois meses. Foi realizada anamnese, exame físico geral (inspeção, frequência cardíaca, frequência respiratória, coloração de mucosas, tempo de preenchimento capilar, temperatura retal e motilidade intestinal), exame neurológico e exames complementares (hemograma, bioquímica renal, hepática e muscular). As alterações encontradas a partir do exame físico incluíram presença de uma massa circular em região lombossacra direita, com aproximadamente $12 \mathrm{~cm}$ de diâmetro e foco central de ulceração, da qual drenava conteúdo enegrecido, que foi coletado e encaminhado para exame citológico. Duas preparações citológicas foram coradas com corante de Wright (coloração tipo Romanowsky) e avaliadas no Laboratório de Patologia Veterinária da UFPR. Observou-se grande quantidade de neutrófilos, acompanhados por moderada quantidade de macrófagos contendo pigmento enegrecido no citoplasma. De acordo com essas características, foi diagnosticada reação inflamatória aguda, predominantemente neutrofílica. Os demais parâmetros do exame físico geral estavam de acordo com o esperado para a espécie.

Ao exame neurológico, o cavalo não demonstrou alterações em nervos cranianos, porém apresentou ataxia, com propriocepção diminuída em membros pélvicos e normal em membros torácicos. Visando a uma melhora no quadro clínico, foi instituída terapia com corticosteroides e antibióticos de largo espectro. No entanto, mesmo sob tratamento, o quadro clínico do animal apresentou agravamento nos dois dias subsequentes, ocorrendo piora da ataxia e do déficit proprioceptivo nos membros pélvicos. Nesse momento, realizou-se o teste do panículo, o qual demonstrou ausência de resposta a estímulo doloroso em região de transição da coluna toracolombar.

Recebido em 22 de fevereiro de 2017

Aceito em 24 de fevereiro de 2017

*Autor para correspondência (corresponding author)

E-mail: petriches@gmail.com 
Procedeu-se a coleta de líquor com o cavalo em estação, sob sedação leve. As amostras foram encaminhadas para avaliação física e química, contagem de células, avaliação citológica, bioquímica e bacteriológica. Foram realizados os testes de Western Blot e PCR para diagnóstico de mieloencefalite protozoária equina (MEP). Os exames físico, químico e bioquímico e a contagem de células e citologia estavam dentro dos valores de normalidade para a espécie. No exame bacteriológico, não houve crescimento bacteriano. Os exames para MEP tiveram resultado negativo.

Quatro dias após o início do quadro clínico, o animal veio a decúbito, devido à paralisia dos membros pélvicos. Levando em consideração o agravamento rápido do quadro e a incapacidade do animal em retornar à posição quadrupedal, mesmo com auxílio e estímulos, optou-se pela realização de eutanásia, seguida de necropsia e exame histopatológico.

$\mathrm{Na}$ necropsia, foi observado um aumento de volume na região lombossacra direita, com aproximadamente $12 \mathrm{~cm}$ de diâmetro e foco central de ulceração, recoberto por crosta enegrecida (Fig. 1A). Ao se rebater o membro posterior direito e a pele das regiões torácica e abdominal, focos de um tecido preto, macio, brilhante, foram observados no subcutâneo ou invadindo grupos de musculatura esquelética: na região abdominal, um foco de tecido macio, preto, com cerca de $1 \mathrm{~cm}$ de diâmetro e contornos irregulares, invadia o músculo oblíquo interno direito do abdômen; outro nódulo com o mesmo aspecto (cerca de $3,5 \mathrm{~cm}$ de diâmetro) foi observado invadindo o músculo oblíquo externo direito do abdômen; em múltiplos focos, nódulos ou massas pretas foram observados ao longo dos músculos intercostais, os quais variavam de $0,5 \mathrm{a}$ $3,5 \mathrm{~cm}$ de diâmetro, e havia infiltração em tecido ósseo envolvendo a quinta e a oitava costelas direitas.

$\mathrm{Na}$ mandíbula, lado direito, uma massa preta e macia infiltrava-se pelo músculo masseter e invadia o osso adjacente, na região da fossa massetérica, estendendo-se para o corpo da mandíbula (Fig. 1B). Essa massa estendia-se rostralmente até o terceiro dente molar direito, envolvendo-o distalmente, porém sem comprometimento da estrutura dentária.

Na região abdominal caudal, em direção à região pélvica, uma massa de tecido macio, preto, foi observada sobre o assoalho da cavidade, na região correspondente à localização do corpo do pênis. Essa massa apresentava cerca de $18 \mathrm{~cm}$ de extensão e $6 \mathrm{~cm}$ de diâmetro e infiltrava-se caudodistalmente no músculo sartório e nos músculos adjacentes (lado esquerdo), comprimindo nervos e vasos sanguíneos dessa região.

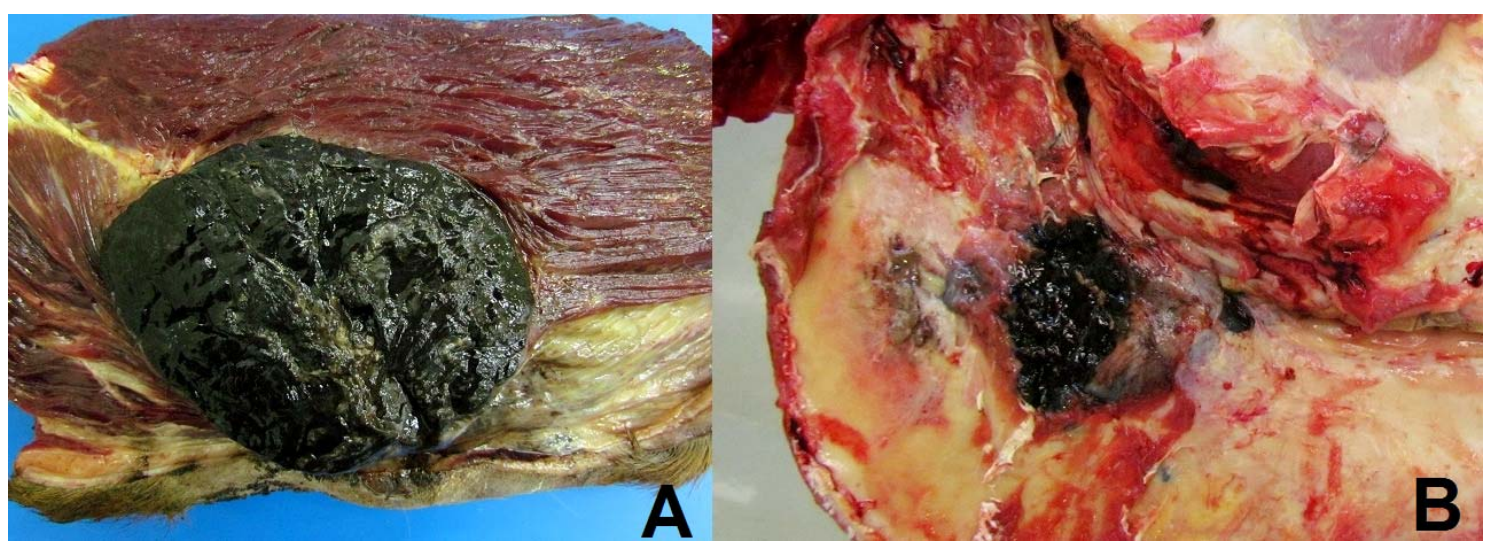

Figura 1. Massas correspondentes a melanoma maligno, encontradas durante necropsia de cavalo de pelagem castanha. A - massa preta e macia, com $12 \mathrm{~cm}$ de diâmetro, localizada em região lombossacra direita, após dissecção; B - massa preta e macia, apresentando infiltração óssea em corpo de mandíbula direita.

Infiltrando a musculatura adjacente aos processos transversos das vértebras torácicas T15 a T17, massas pretas, como as descritas acima, foram observadas. Ao corte, a coloração dos processos transversos e do corpo das vértebras era igualmente preta (Fig. 2A). Adicionalmente, 


\section{Busato et al.}

uma massa de tecido preto, macio, invadia o canal medular entre T15 e T18, comprimindo a medula espinhal (Fig. 2B). Não havia infiltração na meninge ou na medula espinhal. Ainda envolvendo o tecido ósseo, infiltração dessa massa foi também observada na calota craniana, porção rostral do osso frontal, no lado direito
(Fig. 3A). Em órgãos internos, nódulos pretos, macios, variando de 0,3 a mais de $6 \mathrm{~cm}$ de diâmetro foram observados nos pulmões, no coração, no baço, no fígado, na glândula adrenal, nos linfonodos mediastínicos, no cérebro e no cerebelo (Fig. 3B).

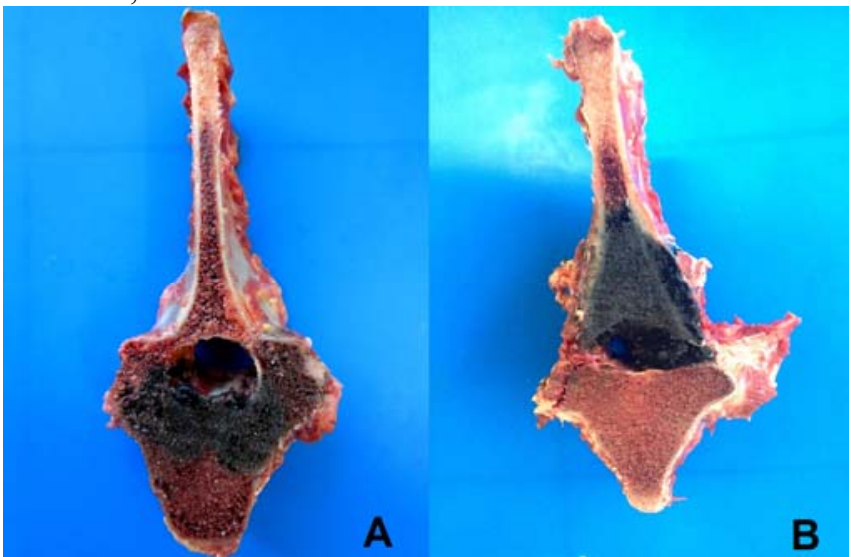

Figura 2. Vértebras torácicas apresentando infiltração por melanoma, em um cavalo de pelagem castanha. A - vértebra torácica em corte, demonstrando infiltração em corpo vertebral e canal medular por melanoma; B - vértebra torácica em corte, demonstrando infiltração de processo transverso e obstrução de mais de $50 \%$ do canal medular por massa preta e macia, correspondente a melanoma.

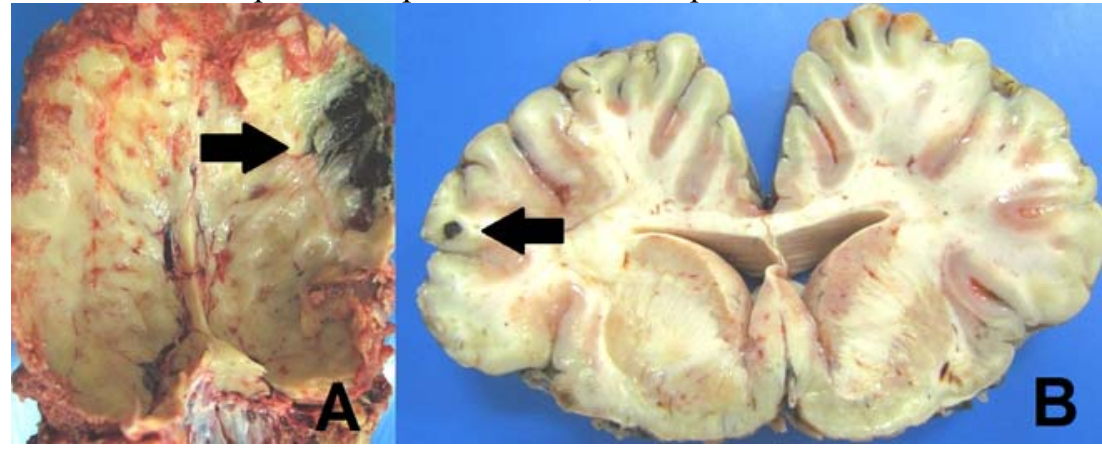

Figura 3. Melanomas em calota craniana e cerebelo, encontrados durante necropsia de um cavalo de pelagem castanha. A - calota craniana com infiltração por uma massa preta e macia (melanoma); B cerebelo com presença de nódulo preto e macio.

De acordo com a histopatologia, as massas e os nódulos pretos observados macroscopicamente correspondiam a uma proliferação neoplásica originária de melanócitos, caracterizada por uma população organizada em um denso lençol celular entremeado por fino a moderado estroma fibrovascular. As células neoplásicas apresentavam moderada a acentuada anisocitose e anisocariose, possuíam o citoplasma pobremente delimitado e repleto de grânulos pretos. O núcleo era arredondado a levemente oval, indistinto em vários focos (devido à quantidade de material citoplasmático). De acordo com os resultados da necropsia e o exame histopatológico, o diagnóstico morfológico foi de melanoma maligno.

Os locais que apresentam maior incidência de melanoma em equinos incluem base da cauda, região perianal e ânus (Thomassian, 2005), no entanto o animal do presente estudo não possuía massas em nenhuma dessas regiões. De acordo com dados publicados por Valentine et al. (2014), a idade média entre nove cavalos não tordilhos que apresentavam melanoma maligno anaplásico em cauda era 16 anos, sendo mais frequente em machos. Entre os casos citados por este autor, a pelagem baia foi a mais acometida 
(seis animais), sendo os três cavalos restantes de pelagens palomina (um), castanha (um) e preta (um). A ocorrência de melanoma em cavalos castanhos é incomum. Tyler e Fox (2003) relataram um caso de melanoma maligno amelanótico em nasofaringe de um cavalo castanho.

A compressão de medula espinhal ocasionada por melanoma já foi relatada em equinos tordilhos (Schott et al., 1990; Rodriguez et al., 1998; Patterson-Kane et al., 2001; MacGillivray et al., 2002), no entanto, no conhecimento dos autores do presente trabalho, e com base na literatura consultada, este é o primeiro caso relatado em cavalo de pelagem castanha.

O primeiro indício de que o caso em questão era de melanoma surgiu a partir da detecção, durante o exame físico, de uma massa ulcerada em região lombossacra direita, a qual drenava conteúdo enegrecido. O exame citológico desse conteúdo revelou a presença de macrófagos contendo pigmento enegrecido no citoplasma. Embora, morfologicamente, tais células sugiram tratar-se de macrófagos com incontinência pigmentar, não se descartou a suspeita de melanoma.

As alterações neurológicas apresentadas pelo animal (ataxia, déficit proprioceptivo e ausência de resposta ao teste do panículo em transição toracolombar) podem ser explicadas pela infiltração neoplásica no canal medular (T15 a T18), nos ossos (vários focos), no encéfalo, bem como pela compressão nos ramos de nervos, como descrito no membro pélvico esquerdo. Esses achados são semelhantes aos encontrados por Patterson-Kane et al. (2001), que descreveram a presença de uma massa melanocítica comprimindo o canal medular entre T10 e T11, o que causou ataxia seguida de decúbito permanente em um cavalo tordilho. A localização das massas encontradas em canal medular por Rodríguez et al. (1998), em uma égua tordilha, foi entre L2 e L4; já Schott et al. (1990) encontraram massas semelhantes em um cavalo tordilho, entre $\mathrm{C} 7$ e $\mathrm{T} 1$ e em uma égua, também tordilha, em C4, C7-T2 e L5-S2. Esses dados demonstram que o melanoma apresenta potencial para acometer todos os segmentos da coluna vertebral.
As infiltrações ósseas (incluindo processos tranversos e corpos vertebrais), assim como a presença de massas na musculatura adjacente às vértebras acometidas, encontradas no presente caso, corroboram os achados obtidos em outros relatos semelhantes (Rodríguez et al., 1998; Patterson-Kane et al., 2001), porém a presença de nódulos em cérebro e cerebelo não foi descrita por esses autores.

Em todos os casos citados anteriormente, os quais envolviam melanoma em canal medular, os cavalos foram submetidos à eutanásia. $\mathrm{O}$ diagnóstico definitivo foi realizado após necropsia, exceto em uma égua prenhe, que apresentava massa entre C7 e T1, na qual foi possível detectar a compressão por meio de mielografia. Essa égua foi submetida a tratamento cirúrgico paliativo (laminectomia dorsal parcial) visando à manutenção de sua gestação, no entanto o animal foi submetido à eutanásia após abortar. $\mathrm{O}$ diagnóstico presuntivo de melanoma como o responsável pela compressão medular foi realizado anteriormente à cirurgia, levando em consideração fatores como a presença de massas compatíveis com melanoma ao redor do ânus e no pescoço e a presença de melanófagos em amostra de líquor coletada por punção lombossacra (Schott et al., 1990). No presente estudo, a análise do líquor coletado por punção atlanto-occipital não demonstrou a presença de melanófagos, no entanto Schott et al. (1990) acreditam que a presença de tais células em sua amostra tenha ocorrido por punção acidental de uma massa propriamente dita, visto que os pesquisadores não encontraram essas células quando a coleta foi realizada por punção atlanto-occipital. Dessa forma, pode-se considerar que a coleta de líquor é uma ferramenta útil, porém pouco sensível, como auxílio no diagnóstico de melanoma no canal medular. Apesar de o melanoma ser infrequente em cavalos não tordilhos, deve-se levar em consideração seu comportamento potencialmente maligno em outras pelagens, como a castanha. Assim, é importante incluir essa neoplasia na lista de diagnósticos diferenciais de massas e/ou nódulos cutâneos e subcutâneos, assim como nos casos suspeitos de compressão medular em cavalos de qualquer pelagem. O exame citológico e/ou histopatológico dos nódulos/massas suspeitos é 
relevante para nortear investigações clínicas e confirmar, presumir ou descartar possíveis diagnósticos. A análise de líquor constitui ferramenta amplamente utilizada como auxílio diagnóstico em afecções relativas ao sistema nervoso central, no entanto nem sempre leva a uma conclusão específica, devendo ser interpretada com atenção e cautela.

Palavras-chave: ataxia, neoplasia equina, melanócitos

\begin{abstract}
This paper describes a case of malignant melanoma in brown coat horse, which had ataxia and proprioceptive deficits in hind limbs, progressing to permanent decubitus. The animal was euthanized and the final diagnosis was based on necropsy and histopathology. At necropsy different masses and / or nodules in skeletal muscle, bone, abdominal cavity, lungs, heart, spleen, liver, adrenal gland, lymph nodes, brain and cerebellum were found. Neurological clinical signs presented by the animal were justified by spinal cord compression caused by melanocytic mass invading the medullary canal of the flow segment of the thoracic spine (between 15th and 18th thoracic vertebrae). This is the first case report of melanoma leading to spinal cord compression in a non-gray horse. Thus, it is important to include this neoplasm in the differential diagnosis list of cutaneous and subcutaneous masses and / or nodules, and in suspected cases of spinal cord compression in horses of any coat.
\end{abstract}

Keywords: ataxia, horse neoplasm, melanocytes

\section{REFERÊNCIAS}

MACGILLIVRAY, K.C.; SWEENEY, R.W.; DEL PIERO, F. Metastatic melanoma in horses. J. Vet. Int. Med., v.16, p.452-456, 2002.

PATTERSON-KANE, J.C.; SANCHEZ, L.C.; UHL, E.W. et al. Disseminated metastatic intramedullary melanoma in an aged grey horse. J. Comp. Pathol., v.125, p.204-207, 2001.

RODRÍGUEZ, F.; FORGA, J.; HERRÁEZ, P. et al. Metastatic melanoma causing spinal cord compression in a horse. Vet. Rec., v.142, p.248249, 1998.

SCHOTT, H.C.; MAJOR, M.D.; GRANT, B.D. et al. Melanoma as a cause of spinal cord compression in two horses. J. Am. Vet. Med. Assoc., v.196, p.1820-1822, 1990.
SUNDBERG, J.P.; BURNSTEIN, T.; PAGE, E.H. et al. Neoplasms of equidae. J. Am. Vet. Med. Assoc., v.170, p.150-152, 1977.

THOMASSIAN, A. Enfermidades dos cavalos. 4.ed. São Paulo: Varela. 2005. 574p.

TYLER, R.; FOX, R. Nasopharyngeal malignant amelanotic melanoma in a gelding age 9 years. Equine Vet. Educ., v.15, p.19-26, 2003.

VALENTINE, B.A.; CALDERWOOD MAYS, M.B.; CHERAMIE, H.S. Anaplastic malignant melanoma of the tail in non-grey horses. Equine Vet. Educ., v.26, p.156-158, 2014. 